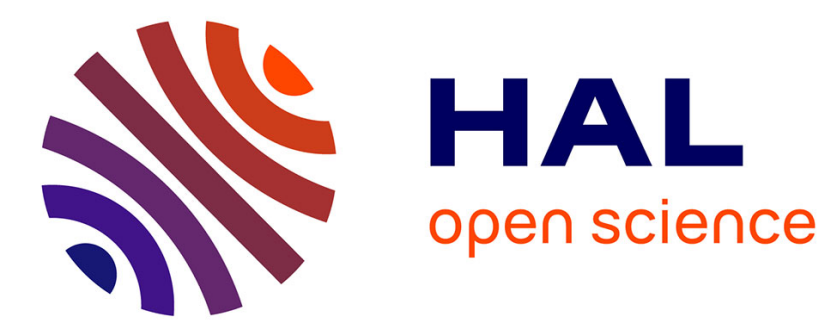

\title{
Molten salt pyrolysis of biomass: The evaluation of molten salt
}

\author{
Kuo Zeng, Xinyi Yang, Yingpu Xie, Haiping Yang, Jun Li, Dian Zhong, \\ Hongyang Zuo, Ange Nzihou, Youjian Zhu, Hanping Chen
}

\section{To cite this version:}

Kuo Zeng, Xinyi Yang, Yingpu Xie, Haiping Yang, Jun Li, et al.. Molten salt pyrolysis of biomass: The evaluation of molten salt. Fuel, 2021, 302, pp.121103. 10.1016/j.fuel.2021.121103 . hal-03247402

\section{HAL Id: hal-03247402 https://imt-mines-albi.hal.science/hal-03247402}

Submitted on 9 Jun 2021

HAL is a multi-disciplinary open access archive for the deposit and dissemination of scientific research documents, whether they are published or not. The documents may come from teaching and research institutions in France or abroad, or from public or private research centers.
L'archive ouverte pluridisciplinaire HAL, est destinée au dépôt et à la diffusion de documents scientifiques de niveau recherche, publiés ou non, émanant des établissements d'enseignement et de recherche français ou étrangers, des laboratoires publics ou privés. 


\title{
Molten salt pyrolysis of biomass: The evaluation of molten salt
}

\author{
Kuo Zeng ${ }^{\mathrm{a}, \mathrm{b}, \mathrm{c}}$, Xinyi Yang ${ }^{\mathrm{a}, \mathrm{b}}$, Yingpu Xie ${ }^{\mathrm{b}}$, Haiping Yang ${ }^{\mathrm{b}, *}$, Jun Li $^{\mathrm{b}}$, Dian Zhong ${ }^{\mathrm{b}}$, \\ Hongyang Zuo $^{\mathrm{b}}$, Ange Nzihou ${ }^{\mathrm{d}}$, YouJian Zhu ${ }^{\mathrm{b}}$, Hanping Chen ${ }^{\mathrm{b}, *}$ \\ ${ }^{a}$ China-EU Institute for Clean and Renewable Energy, Huazhong University of Science and Technology, Wuhan 430074, PR China \\ ${ }^{\mathrm{b}}$ State Key Laboratory of Coal Combustion, Huazhong University of Science and Technology, 1037 Luoyu Road, Wuhan, Hubei 430074, PR China \\ ${ }^{c}$ Shenzhen Huazhong University of Science and Technology Research Institute, Shenzhen 523000, China \\ ${ }^{\mathrm{d}}$ Université de Toulouse, Mines Albi, UMR CNRS 5302, Centre RAPSODEE, Campus Jarlard, F-81013 Albi cedex 09, France
}

Keywords:

Biomass

Pyrolysis

Molten salt

Thermal stability

Thermodynamic simulation

\begin{abstract}
A B S T R A C T
To identify the performance and mechanism of variant molten salts during biomass pyrolysis in molten salt, the thermogravimetric and differential scanning calorimetry (TG-DSC) analyzer, fixed-bed reactor and thermodynamic equilibrium simulation were applied to study the thermal melting characteristics and stability of molten salt as well as the selectivity for biomass pyrolysis products. The $\mathrm{KCl}-\mathrm{ZnCl}_{2}$ is appropriate for the preparation of $\mathrm{H}_{2}$-rich gas and the carbon material with abundant mesoporous structure due to its activation effect. At $850{ }^{\circ} \mathrm{C}$, the pyrolysis gas obtained from $\mathrm{KCl}-\mathrm{ZnCl}_{2}$ contained $42.22 \mathrm{vol} \% \mathrm{H}_{2}$ with the $\mathrm{H}_{2} / \mathrm{CO}$ ratio reaching 1.69 . The carbonates demonstrated excellent improvement for the gas composition of biomass pyrolysis products, with 75.43 vol\% and 70.52 vol\% syngas $\left(\mathrm{H}_{2}+\mathrm{CO}\right)$ collected from the $\mathrm{Li}_{2} \mathrm{CO}_{3}-\mathrm{K}_{2} \mathrm{CO}_{3}$ and $\mathrm{Li}_{2} \mathrm{CO}_{3}-\mathrm{Na}_{2} \mathrm{CO}_{3}-\mathrm{K}_{2} \mathrm{CO}_{3}$ pyrolysis systems at $850{ }^{\circ} \mathrm{C}$ respectively. With the presence of carbonates, the bio-oil and char prepared by biomass pyrolysis also achieved better quality. The thermodynamic simulation revealed the shifting (formation of $\mathrm{Li}_{2} \mathrm{O}$ ) of molten salt composition during biomass pyrolysis. The interaction between $\mathrm{Li}_{2} \mathrm{CO}_{3}$ and char under high temperature explained the high yield of $\mathrm{CO}$ in pyrolysis gas products, also resulted in the consumption of salts and limited the sustainable use of the molten salt pyrolysis system.
\end{abstract}

\section{Introduction}

Pyrolysis of biomass is the direct thermal decomposition of the carbonaceous feedstocks in the absence of oxygen to obtain an array of solid, liquid and gas products, which has been widely used for commercial production of biomass derivatives, such as fuels, solvents, chemicals etc. [1]. The atmosphere of pyrolysis is usually provided by sweeping inert gas including argon or nitrogen. However, the studies on conventional pyrolysis within gaseous atmosphere were followed by several challenges, such as incomplete reaction and the poor quality of the pyrolysis products. For example, the pyrolysis oil from biomass waste was found to be highly oxygenated and complex, and chemically unstable in need of being upgraded [2]. One of the promising methods is to apply molten salt into the thermochemical conversion of the biomass to provide a liquid reaction environment, during which molten salt can be simultaneously viewed as heat carrier, catalyst and solvent [3]. Considerable researches [3-7] have been conducted to take advantage of molten salts, such as: rapid heating value, enhancement of heat transfer and catalyst effect. Among the molten salts, the ease to get alkali metal distinguish themselves by their excellent catalysis effect [8]. Therefore, alkali metal salts are usually the prior option as pyrolysis medium. Generally, the phosphate, borate and silicate of the alkali metals would form polymerized glassy compound at the temperature of biomass pyrolysis. Thus, the other oxygenates (carbonate, nitrate and sulfate) and the chlorides of the alkali metals are considered as appropriate medium.

With the aim of determining the adaptability of different molten salt kinds to biomass pyrolysis, the characteristics of thermal melting, thermal stability and chemical stability of molten salts are important factor. Peng et al. [9] found that the ternary nitrate salt showed its favorable stability below $500{ }^{\circ} \mathrm{C}$. Olivares et al. [10] discovered that the eutectic carbonate $\left(\mathrm{Li}_{2} \mathrm{CO}_{3}-\mathrm{Na}_{2} \mathrm{CO}_{3}-\mathrm{K}_{2} \mathrm{CO}_{3}\right)$ remained stable under a blanket gas atmosphere of $\mathrm{CO}_{2}$ up to at least $1000^{\circ} \mathrm{C}$. Pramod et al. [11] prepared mixtures of potassium nitrate, calcium nitrate and lithium nitrate in different proportions, which showed better thermal stability up to a temperature of $600{ }^{\circ} \mathrm{C}$. In addition, Serrano et al. [12] observed that the eutectic salt $\left(\mathrm{NaNO}_{3}-\mathrm{KNO}_{3}\right)$ would decompose if the

\footnotetext{
* Corresponding authors.

E-mail addresses: yhping2002@163.com (H. Yang), yhping2002@163.com (H. Chen).
} 
Table 1

Proximate and ultimate analysis of cotton stalk.

\begin{tabular}{|c|c|c|c|c|c|c|c|c|c|c|}
\hline \multirow[t]{2}{*}{ Sample } & \multicolumn{4}{|c|}{ Proximate (wt.\%) ad } & \multicolumn{5}{|c|}{ Ultimate (wt.\%) ad } & \multirow[t]{2}{*}{ LHV (MJ/kg) } \\
\hline & M & $\mathrm{V}$ & A & $\mathrm{FC}$ & $\mathrm{C}$ & $\mathrm{H}$ & $\mathrm{N}$ & $\mathrm{S}$ & $\mathrm{O}^{*}$ & \\
\hline Cotton Stalk & 1.86 & 77.49 & 4.61 & 16.04 & 46.56 & 6.04 & 0.79 & 0.20 & 41.82 & 17.18 \\
\hline
\end{tabular}

ad: air dry basis; *: calculated by difference; M: moisture; V: volatiles; FC: fixed carbon; Ad: ash.

temperature was higher than $560^{\circ} \mathrm{C}$, demonstrating its inadaptability to biomass pyrolysis. Therefore, the stability of molten salt under high temperature with the presence of carbonaceous feedstock is also important for biomass pyrolysis.

The quality of the pyrolysis products will directly determine the industrial applicability of the pyrolysis process. Thus, the selectivity of molten salt to biomass pyrolysis products is the decisive factor to evaluate molten salts. The upgrading effect on different pyrolysis products of ternary carbonate have been widely reported [13-15]. Adinberg et al. [4] observed the enhancement of the selectivity regarding the gas product with the molten $\mathrm{Na}_{2} \mathrm{CO}_{3}-\mathrm{K}_{2} \mathrm{CO}_{3}$ during the fast pyrolysis of cellulose particles. Zeng et al. [16] found a significant yield increase of syngas at $750-850{ }^{\circ} \mathrm{C}$ with the eutectic $\mathrm{Li}_{2} \mathrm{CO}_{3}-\mathrm{Na}_{2} \mathrm{CO}_{3}-\mathrm{K}_{2} \mathrm{CO}_{3}$ compared with the fast pyrolysis of biomass. Moreover, Wei et al. [5] obtained phenols content reaching up to $67 \%$ in the pyrolysis of digestate. And Yin et al. [13] found that the good dissolving ability of alkaline carbonate molten helped to produce high surface area carbon which can be used as capacitive carbon.

Although molten carbonate is the preferred medium for biomass pyrolysis in recent years, other molten salts have also been focused due to the excellent performance. Jiang et al. [3] conducted pyrolysis of cellulose within five kind of mixed molten salts, where $\mathrm{ZnCl}_{2}$ made the yield of bio-oil product reach maximum due its catalytic effects on biomass pyrolysis. Nygard et al. [17] investigated the thermal behavior of wood particles in pyrolysis using different mixtures of molten salts (FLiNaK, $(\mathrm{LiNaK})_{2} \mathrm{CO}_{3}, \mathrm{ZnCl}_{2}-\mathrm{KCl}, \mathrm{KNO}_{3}-\mathrm{NaNO}_{3}$ ), and concluded that the nitrate mixture was not suitable for pyrolysis. Yeboah et al. [18] focused on the catalyst effect of the carbonate, nitrate and sulfate of the alkali metals on gasification. It turned out that among the three types of oxygenates, the catalytic activity ranged from high to low as lithium salts, potassium salts and sodium salts in sequence. It can be seen that different kinds of molten salt being introduced to biomass pyrolysis would present various performance. However, the possible mechanisms and the intrinsic relationship between the properties of different kinds of molten salts and their selectivity for pyrolysis products are still not clear.

Based on the previous analysis, in view of the thermochemical conversion of biomass in molten salts, the chloride, carbonate and sulfate of alkali metals lithium, sodium, potassium are suitable for the potential salt to be used in industry. In addition, $\mathrm{ZnCl}_{2}$ is included $\left(\mathrm{ZnCl}_{2}-\mathrm{KCl}\right.$ especially) due to its catalytic performance reported in recent studies of the pyrolysis [17,19-23]. In this study, the thermal characteristics of seven common molten salts were evaluated according to their composition (binary and ternary) and anion species (chlorides, carbonates and sulfates) by the thermogravimetric and differential scanning calorimetry (TG-DSC) analyzer. The selectivity of different molten salt to pyrolysis product as an evaluation index was investigated with the biomass pyrolysis performed in fixed-bed reactor at $850{ }^{\circ} \mathrm{C}$ compared to the pyrolysis of cotton stalk without molten salt. In addition, the decomposition of molten salt and its participation in biomass pyrolysis was investigated through the HSC simulation of biomass pyrolysis within different systems. And the intrinsic relevance of the characteristics of molten salt and its effect on pyrolysis was explained with a preliminary attempt.

\section{Experimental}

\subsection{Materials}

The biomass raw material selected for the experiment is the cotton stalk, a typical agriculture waste sampled from Ezhou (Hubei, China). After crushing and sieving, samples of 0.1 to $0.4 \mathrm{~mm}$ were collected, dried in an oven at $105^{\circ} \mathrm{C}$ for $24 \mathrm{~h}$, and then put into glass sample bottles and sealed for subsequent use. The proximate analysis of the sample was tested by the TGA-2000 analyzer (Las Navas, Spain), and the ultimate analysis was performed by the CHNS/O element analyzer (Vario Micro Cube, Germany). The lower heating value (LHV) was obtained by bomb calorimetry (Parr 6300, USA). The analysis data is shown in Table 1.

As mentioned in introduction, 9 kinds of alkali metal salts ( $\mathrm{LiCl}$,

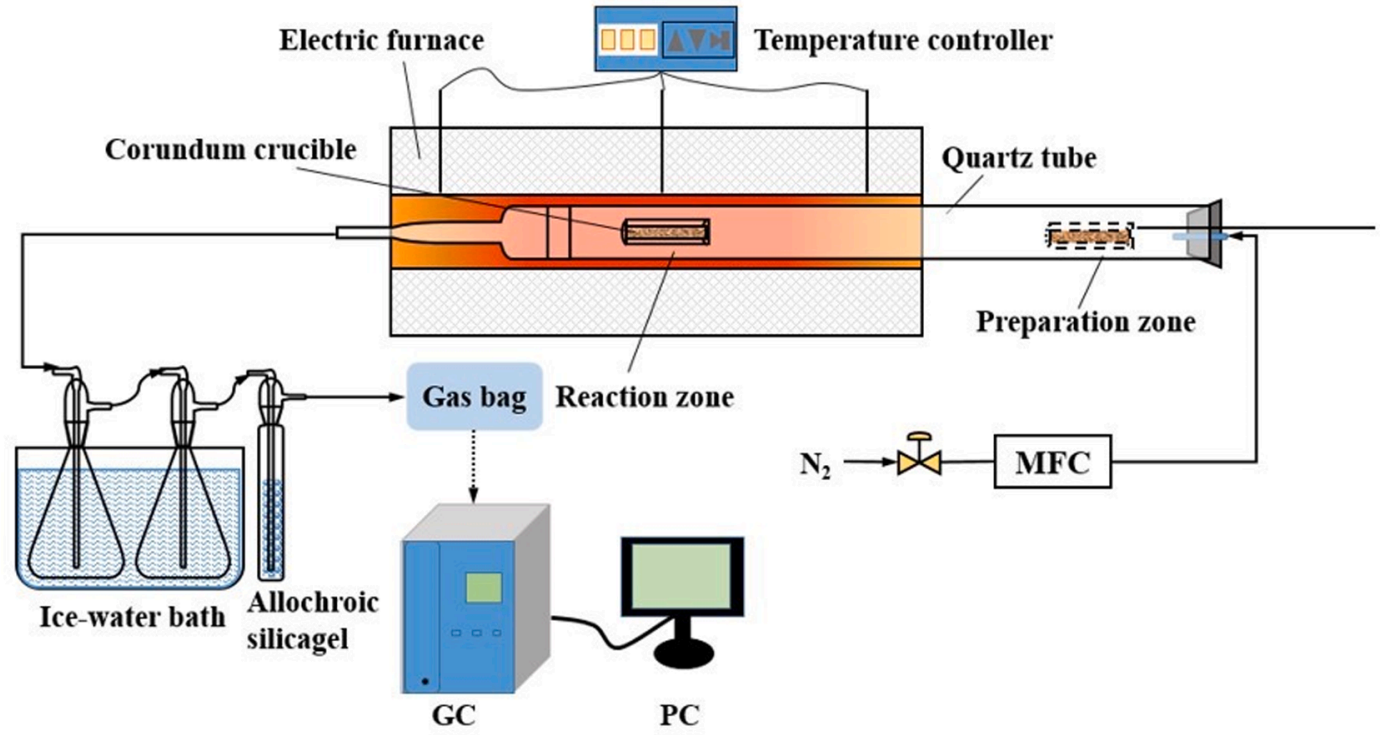

Fig. 1. Schematic of molten salt pyrolysis setup. 
$\mathrm{NaCl}, \mathrm{KCl}, \mathrm{Li}_{2} \mathrm{CO}_{3}, \mathrm{Na}_{2} \mathrm{CO}_{3}, \mathrm{~K}_{2} \mathrm{CO}_{3}, \mathrm{Li}_{2} \mathrm{SO}_{4}, \mathrm{Na}_{2} \mathrm{SO}_{4}$ and $\mathrm{K}_{2} \mathrm{SO}_{4}$ ) and $\mathrm{ZnCl}_{2}$ were selected. All of them were purchased from Sinopharm Chemical Reagent Co., Ltd (Shanghai, China) with analytical purity $>99 \%$. The basic data of the physical and chemical properties of these salts are shown in appendix Table A1. Using the salts selected above, seven molten salt systems were prepared: including 4 binary molten salts ( $\mathrm{LiCl}-\mathrm{KCl}, \mathrm{KCl}-\mathrm{ZnCl}_{2}, \mathrm{Li}_{2} \mathrm{CO}_{3}-\mathrm{K}_{2} \mathrm{CO}_{3}$ and $\mathrm{Li}_{2} \mathrm{SO}_{4}-\mathrm{K}_{2} \mathrm{SO}_{4}$ ) and 3 ternary molten salts ( $\mathrm{LiCl}-\mathrm{NaCl}-\mathrm{KCl}, \mathrm{Li}_{2} \mathrm{CO}_{3}-\mathrm{Na}_{2} \mathrm{CO}_{3}-\mathrm{K}_{2} \mathrm{CO}_{3}$ and $\mathrm{Li}_{2} \mathrm{SO}_{4}$ $\mathrm{Na}_{2} \mathrm{SO}_{4}-\mathrm{K}_{2} \mathrm{SO}_{4}$ ). During the preparation process: take two or three kinds of salts of equal amount, mix them mechanically and grind them fully in an agate mortar, place the mixed molten salts in a $120^{\circ} \mathrm{C}$ oven for $24 \mathrm{~h}$ drying, then put it into a sample bottle and seal it for later use. For the performance of each molten salt system in biomass pyrolysis, they were compared with the original cotton stalk sample which will be denoted as CS in the rest of this article. For the analysis of pyrolysis products in different molten salts, their samples of gas, oil, and char products will be marked as "Molten salt system".

\subsection{Experimental setup and procedure}

The thermal stability and melting point of the molten salt were tested by the integrated thermal analyzer (LABSYS EVO 1150, Setaram, France) with thermogravimetric-differential calorimetry (TG-DSC) sensor. Weigh $10 \mathrm{mg}$ of salts and carefully transfer it to the sample crucible. The thermogravimetric heating program is set as follows: The temperature of the reactor was increased from room temperature to $105^{\circ} \mathrm{C}$ at a heating rate of $10{ }^{\circ} \mathrm{C} / \mathrm{min}$ and maintained at $105{ }^{\circ} \mathrm{C}$ for 10 min. Followed by climbing to $850{ }^{\circ} \mathrm{C}$ at a rate of $10{ }^{\circ} \mathrm{C} / \mathrm{min}$, and then stopped heating. All the reactions are operated under a nitrogen atmosphere with a $100 \mathrm{~mL} / \mathrm{min}$ flow rate.

The experimental setup for biomass pyrolysis in molten salt includes a quartz tube reactor, a tube furnace with a temperature control system, a gas controller, a gas condensing device with an ice-water bath, and a gas collection unit shown in Fig. 1. In each experiment, about $1 \mathrm{~g}$ of biomass sample and $5 \mathrm{~g}$ of molten salt were taken in an agate mortar, ground and mixed uniformly, and then used for pyrolysis experiments. For comparison, $5 \mathrm{~g}$ of silicon carbide and $1 \mathrm{~g}$ of sample were mixed and pyrolyzed as a blank group. Place the mixed sample to a semi-circular arc corundum boat (length $100 \mathrm{~mm}$, height $18 \mathrm{~mm}$ ). Then the corundum boat was placed in the preparation zone of the reaction tube, and $200 \mathrm{~mL} / \mathrm{min}$ of $\mathrm{N}_{2}$ was introduced. When the reactor is heated to the setting temperature $\left(850{ }^{\circ} \mathrm{C}\right)$ and remains stable, the corundum boat is quickly pushed to the reaction zone in the middle of the furnace, and stays for $30 \mathrm{~min}$. It should be noted that the biomass could be well immersed and dispersed in the molten salt in our device when the ratio of molten salt to biomass reached 5, which can make full use of the catalytic performance of molten salt. Moreover, under the condition of ensuring that all salts can be fully melted, the pyrolysis temperature of $850{ }^{\circ} \mathrm{C}$ is selected based on our previous work to obtain higher quality pyrolysis products [14].

During the pyrolysis, condensable components are condensed into liquid oil within the flasks through the ice-water bath, while noncondensable gas is collected in a gas bag after drying and purification for subsequent analysis. When the reaction is over, the solid residue is cooled to room temperature with continuous $\mathrm{N}_{2}$ gas flow. The solid residue in the corundum boat may be a mixture of molten salt, metal oxide and char. Firstly, wash the solid residue with excess deionized water and corresponding acid (such as $\mathrm{HCl}$, etc.) and filter with suction, then weigh it after drying to obtain the char yield. As for condensed oil collection, $5 \mathrm{~mL}$ acetone is used for the lavation of the flask and connected silicone tube.

\subsection{Analysis of pyrolysis products}

The pyrolysis gas products were analyzed with gas chromatograph (PANNA A91, Changzhou Pannuo Instrument Co., Ltd, China). $\mathrm{H}_{2}, \mathrm{~N}_{2}$,
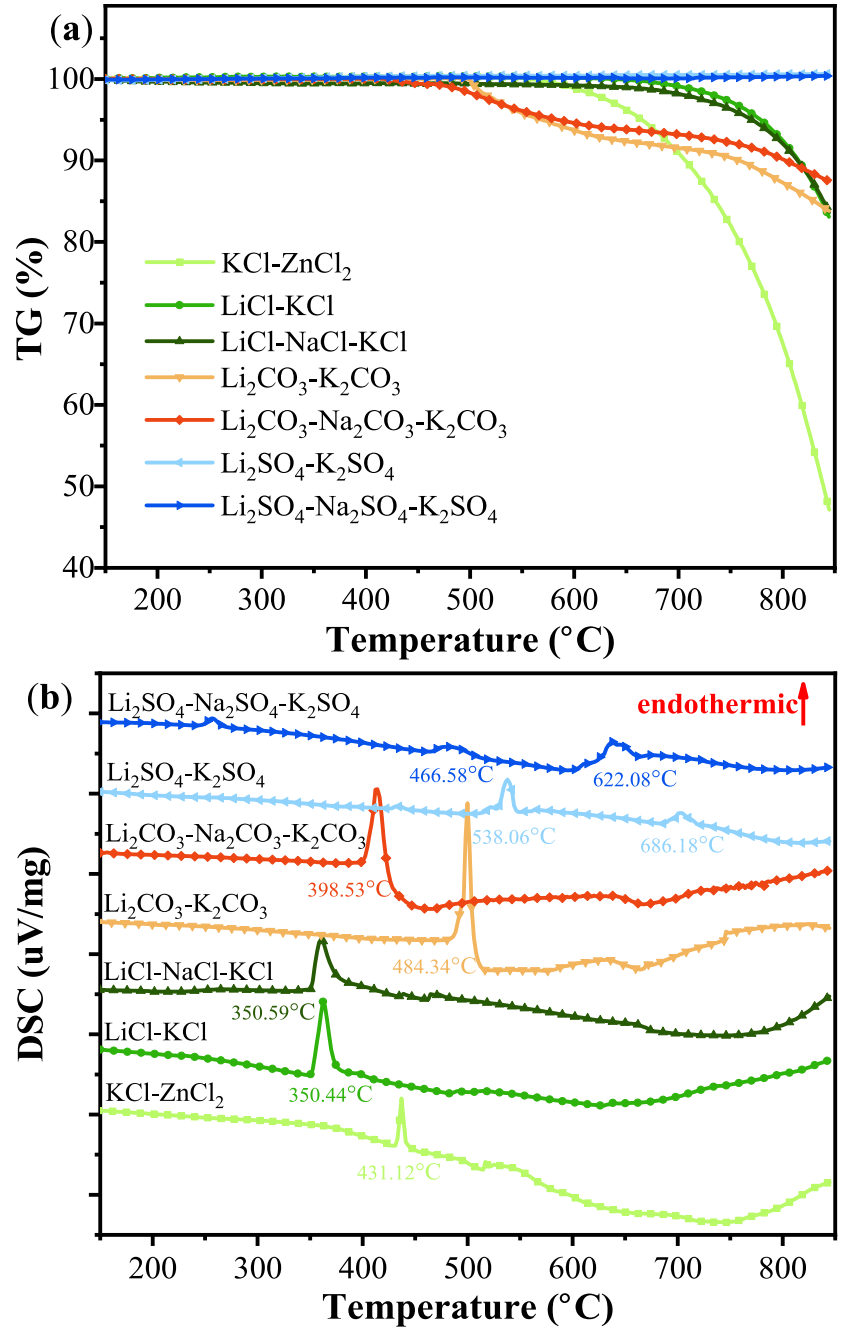

Fig. 2. TG-DSC curves of seven molten salt systems: (a) TG and (b) DSC.

$\mathrm{O}_{2}, \mathrm{CO}_{2}, \mathrm{CH}_{4}$ and $\mathrm{CO}$ were separated by Porapak Q column and $5 \mathrm{~A}$ zeolite molecular sieve column with $\mathrm{He}$ as carrier gas and analyzed by a thermal conductivity detector (TCD). Olefins and alkanes $\left(\mathrm{C}_{2+}\right)$ were separated using a $\mathrm{Al}_{2} \mathrm{O}_{3} / \mathrm{KCl}$ capillary column with $\mathrm{N}_{2}$ as carrier gas and analyzed by a flame ionization detector (FID). The other details of the instrument and the calculation method of gas products have been described in our previous work [14]. Besides, the lower heating value (LHV, MJ $/ \mathrm{Nm}^{3}$ ) of the pyrolysis gas was obtained by the following equation [24]:

$\mathrm{LHV}_{\text {gas }}=12.6 \times \mathrm{CO}+10.8 \times \mathrm{H}_{2}+35.8 \times \mathrm{CH}_{4}+66.5 \times \mathrm{C}_{2+}$

where $\mathrm{CO}, \mathrm{H}_{2}, \mathrm{CH}_{4}$ and $\mathrm{C}_{2+}$ (alkanes and alkenes above $\mathrm{C}_{2}$ ) are the volume fraction (vol.\%) of this specie in the whole gas product.

Another parameter Gas Energy Conversion Efficiency (GECE) was used to indicate the percentage of biomass pyrolysis gas product energy to the input biomass energy, as follows:

$\mathrm{GECE}=\left(\sum \mathrm{v}_{\mathrm{i}} \times \mathrm{LHV}_{\text {gas }}\right) /\left(\mathrm{m}_{\text {biomass }} \times \mathrm{LHV}_{\text {biomass }}\right)$

where $v_{i}$ is the volume of each component $\left(\mathrm{H}_{2}, \mathrm{CO}, \mathrm{CO}_{2}, \mathrm{CH}_{4}\right.$ and $\left.\mathrm{C}_{2+}\right)$ of the gas products.

The organic components in the oil were analyzed with a gas chromatography-mass spectrometer (GC-MS, 7890A/5975C, Agilent, USA). The GC-MS injector hold temperature of $280^{\circ} \mathrm{C}$, and the spilt rate was $20: 1$. The GC oven was heated from $40^{\circ} \mathrm{C}$ to $300^{\circ} \mathrm{C}$ at a heating rate of $10{ }^{\circ} \mathrm{C} / \mathrm{min}$. The detected samples were separated using a capillary 
column named HP-5MS (30 $\mathrm{m} \times 0.25 \mathrm{~mm} \times 0.25 \mu \mathrm{m}$, Agilent). Mass spectra were obtained using a quadripole analyzer with $70 \mathrm{eV}$ electron impact (EI) ionization between 40 and 600 a.m.u. [25]. All the compounds were identified based on NIST mass spectral data library with response factors for GC quantification determined by internal standard method [26].

The ultimate analysis of the collected char was tested by a CHNS/O elementary analyzer (Vario Micro Cube, Germany). The specific surface area and pore size distribution were analyzed with Surface Area and Porosity analyzer (TriStar II, Micromeritics Instrument Corp., Norcross, USA). Nitrogen adsorption isotherm was obtained at the temperature of $-196{ }^{\circ} \mathrm{C}$ in the relative pressures $\left(\mathrm{P} / \mathrm{P}_{0}\right)$ range between 0.05 and 0.99 . Specific surface area $\left(\mathrm{S}_{\mathrm{BET}}\right)$ and micropore area $\left(\mathrm{S}_{\mathrm{mic}}\right)$ are calculated by Brunauer-Emmett-Teller (BET) equation. The micropore volume $\left(\mathrm{V}_{\mathrm{mic}}\right)$ was calculated by the t-plot method and the total pore volume $\left(\mathrm{V}_{\text {total }}\right)$ was calculated by the total volume of single point adsorption. The average pore size (D) and pore size distribution were calculated by the Barret-Joyner-Halenda (BJH) method.

\section{Results and discussion}

\subsection{Thermal melting characteristics and stabilities}

The thermal melting characteristics and stabilities are analyzed based on the TG-DSC curves of seven molten salt systems, as shown in Fig. 2. From the thermogravimetric (TG) curve shown in Fig. 2(a), it can be seen that the weight loss of all selected molten salts before $500{ }^{\circ} \mathrm{C}$ is negligible, which may be caused by the evaporation of a small amount of water in the molten salt. Then as the temperature continued to rise, chlorides and carbonates began to lose weight, and there were obvious differences in the weight loss behavior of different types of molten salts. In addition, it can be noted that the decomposition temperature of $\mathrm{LiCl}$, $\mathrm{NaCl}, \mathrm{KCl}, \mathrm{Na}_{2} \mathrm{CO}_{3}, \mathrm{~K}_{2} \mathrm{CO}_{3}$ and $\mathrm{Na}_{2} \mathrm{SO}_{4}$ shown in appendix Table A is higher than the pyrolysis temperature, indicating that these six salts have no effect on the thermogravimetric characteristics of the molten salt system.

Alkali metal chlorides demonstrate good thermal stability under $700{ }^{\circ} \mathrm{C}$. The weight loss of the molten chloride is mainly due to the evaporation loss caused by the sweeping of the carrier gas after the melting of molten salt. At higher temperature especially above $740{ }^{\circ} \mathrm{C}$, the molten salt evaporates faster with more weight loss [27]. $\mathrm{KCl}-\mathrm{ZnCl}_{2}$ exhibits more significant weight loss behavior than alkali metal chlorides. At $850{ }^{\circ} \mathrm{C}$, the weight loss of $\mathrm{KCl}-\mathrm{ZnCl}_{2}$ reaches $53.4 \%$. It shows the poor thermal stability of molten salt $\mathrm{KCl}-\mathrm{ZnCl}_{2}$ under high temperature. Alkali metal carbonates $\mathrm{Li}_{2} \mathrm{CO}_{3}-\mathrm{K}_{2} \mathrm{CO}_{3}$ and $\mathrm{Li}_{2} \mathrm{CO}_{3}-\mathrm{Na}_{2} \mathrm{CO}_{3}-\mathrm{K}_{2} \mathrm{CO}_{3}$ have obvious weight loss behavior at $530{ }^{\circ} \mathrm{C}$, which reaches $16.2 \%$ and $12.5 \%$ at $850{ }^{\circ} \mathrm{C}$ respectively. On the one hand, the weight loss of carbonate is due to the evaporation loss after the molten salt melts. On the other hand, it is possible that the $\mathrm{Li}_{2} \mathrm{CO}_{3}$ decomposes and releases $\mathrm{CO}_{2}$ above $750{ }^{\circ} \mathrm{C}$ resulting in the weight loss [28]. It can also explain the weight loss of the binary carbonate $\mathrm{Li}_{2} \mathrm{CO}_{3}-\mathrm{K}_{2} \mathrm{CO}_{3}$ at $850{ }^{\circ} \mathrm{C}$ is greater than the ternary carbonate $\mathrm{Li}_{2} \mathrm{CO}_{3}-\mathrm{Na}_{2} \mathrm{CO}_{3}-\mathrm{K}_{2} \mathrm{CO}_{3}$. In addition, the decomposition properties of carbonates at high temperatures are greatly influenced by the atmosphere [10]. The absence of $\mathrm{CO}_{2}$ atmosphere in this case undermines the thermal stability of carbonates. As for the alkali metal sulfates, there is no weight loss for $\mathrm{Li}_{2} \mathrm{SO}_{4}-\mathrm{K}_{2} \mathrm{SO}_{4}$ and $\mathrm{Li}_{2} \mathrm{SO}_{4}$ $\mathrm{Na}_{2} \mathrm{SO}_{4}-\mathrm{K}_{2} \mathrm{SO}_{4}$ heated to $850{ }^{\circ} \mathrm{C}$, indicating the molten sulfates have good thermal stability.

From the differential scanning calorimetry (DSC) curves (Fig. 2(b)), it can be seen that for each selected molten salt system there is an endothermic melting peak. The starting temperature of the melting peak in the DSC curve is the melting point of the molten salt. It can be found that the melting point of $\mathrm{KCl}-\mathrm{ZnCl}_{2}$ is $431{ }^{\circ} \mathrm{C}$. The melting points of LiCl$\mathrm{KCl}$ and $\mathrm{LiCl}-\mathrm{NaCl}-\mathrm{KCl}$ are basically the same, and both begin to melt at around $350^{\circ} \mathrm{C}$. The above results are consistent with the melting point data published in the literature [29-32]. For the carbonate system, the

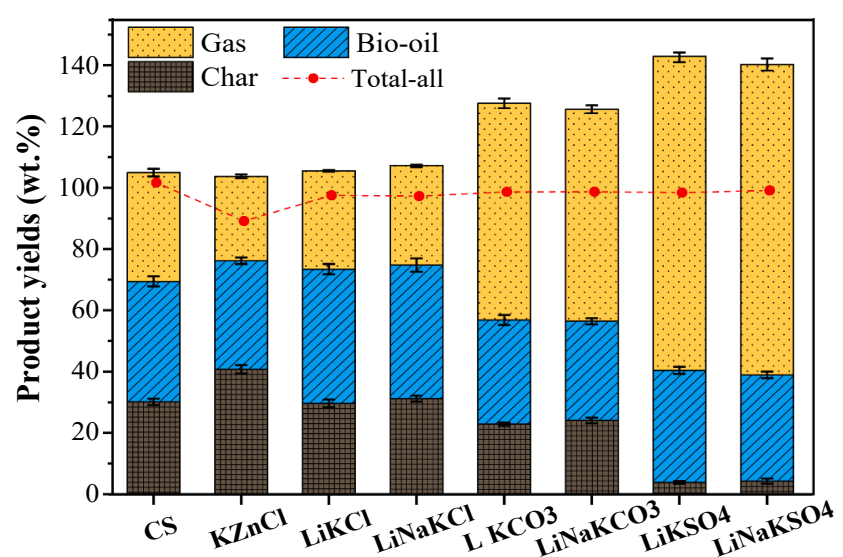

Fig. 3. Product yields of CS pyrolysis and CS pyrolysis within different molten salt systems.

melting point of the binary carbonate $\mathrm{Li}_{2} \mathrm{CO}_{3}-\mathrm{K}_{2} \mathrm{CO}_{3}$ is $484{ }^{\circ} \mathrm{C}$, which is significantly higher than the $398{ }^{\circ} \mathrm{C}$ of the ternary carbonate $\mathrm{Li}_{2} \mathrm{CO}_{3}$ $\mathrm{Na}_{2} \mathrm{CO}_{3}-\mathrm{K}_{2} \mathrm{CO}_{3}$. It endows the ternary carbonate a wider temperature range for biomass thermal conversion. There are obvious fluctuations after the melting peak for molten chlorides and molten carbonates, which is caused by the change in the amount of molten salt sample caused by the evaporation loss after the melting of the molten salt. Different from other molten salts, there is more than one endothermic peak in the duration of sulfate melting. This is due to the endothermic peak formed by the change of the solid crystal form of sulfate before melting.

\subsection{Pyrolysis adaptability}

\subsubsection{Pyrolysis product distribution}

The pyrolysis products distribution and overall mass balance of the cotton stalk with and without molten salt are shown in Fig. 3. The error bars here indicate 95\% confidence intervals. The "Total-all" shows the ratio of initial mass to final mass of the salts and biomass together. The "Total-all" value ranges from $85 \%$ to $110 \%$ in this study.

In high temperature pyrolysis of CS, the yield of char product was $29.1 \mathrm{wt} \%$, which of oil and gas products was $38.1 \mathrm{wt} \%$ and $34.5 \mathrm{wt} \%$, respectively. The addition of $\mathrm{KCl}-\mathrm{ZnCl}_{2}$ increased the char yield to 39.4 $\mathrm{wt} \%$, while the yields of gas and liquid decreased. This is due to the strong dehydration capacity of $\mathrm{ZnCl}_{2}$ under thermal treatment, resulting in a significant reduction in carbonization temperature of biomass components and shifting of decomposition pathways by suppressing tar formation [33]. The "Total-all" value within $\mathrm{KCl}-\mathrm{ZnCl}_{2}$ deviated from $100 \%$ greatly because the salt escaped from the pyrolysis reactor after its evaporation as mentioned in previous section. As for the alkali metal chlorides $\mathrm{LiCl}-\mathrm{KCl}$ and $\mathrm{LiCl}-\mathrm{NaCl}-\mathrm{KCl}$, they have little effect on the distribution of pyrolysis products except for the slight increase of oil products and the slight decrease in gas products. For all the samples obtained from chlorides, the mass balance interval of the pyrolysis products is $100-104 \%$. This is the appearance that the chlorides didn't participate in the pyrolysis reaction.

Under the influence of $\mathrm{Li}_{2} \mathrm{CO}_{3}-\mathrm{K}_{2} \mathrm{CO}_{3}$ and $\mathrm{Li}_{2} \mathrm{CO}_{3}-\mathrm{Na}_{2} \mathrm{CO}_{3}-\mathrm{K}_{2} \mathrm{CO}_{3}$, the yields of char and oil decreased, while the gas yield increased significantly to $68.6 \mathrm{wt} \%$ and $67.1 \mathrm{wt} \%$, compared with that of CS. This phenomenon can be attributed to: (1) Alkali carbonate can promote the secondary cracking of tar to produce more small molecules of gas so that the oil yield is reduced and the gas yield is increased [34,35]; (2) Char reacts with carbonate to produce more gas, which reduces the char yield and further increases the gas yield [36]. Additionally, the mass balance of pyrolysis products reached more than $120 \%$, indicating that carbonates were involved in the pyrolysis reaction in this case.

With the addition of $\mathrm{Li}_{2} \mathrm{SO}_{4}-\mathrm{K}_{2} \mathrm{SO}_{4}$ and $\mathrm{Li}_{2} \mathrm{SO}_{4}-\mathrm{Na}_{2} \mathrm{SO}_{4}-\mathrm{K}_{2} \mathrm{SO}_{4}$, the 


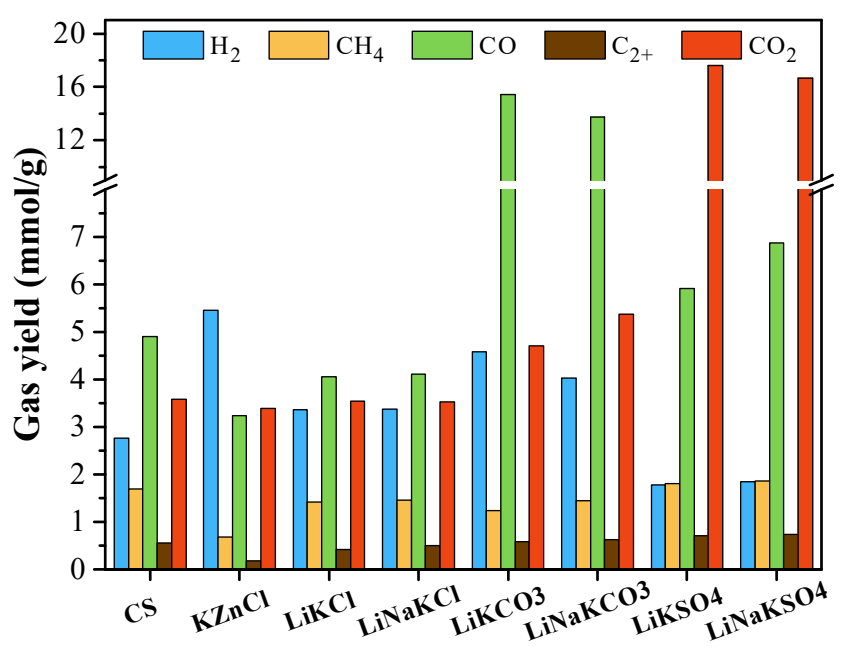

Fig. 4. Gas yield of CS pyrolysis and CS pyrolysis within different molten salt systems.

distribution of pyrolysis products changed greatly. The yields of char decreased significantly to $3.56 \mathrm{wt} \%$ and $4.01 \mathrm{wt} \%$, respectively. Meanwhile, the gas yield increased significantly to $98-99 \mathrm{wt} \%$. The mass balance of the pyrolysis products reached more than $130 \%$, indicating that sulfates participated in the pyrolysis reaction and released a large amount of gas. The possible pathways of this will be explained in detail in the analysis of pyrolysis gas products

\subsubsection{Gas product}

Fig. 4 showed the pyrolysis gas yield based on biomass with various molten salts compared to that without molten salt. The pyrolysis gas products mainly include $\mathrm{H}_{2}, \mathrm{CO}, \mathrm{CO}_{2}$, and a small amount of $\mathrm{CH}_{4}$ and $\mathrm{C}_{2+}$. For $\mathrm{KCl}-\mathrm{ZnCl}_{2}$, the $\mathrm{H}_{2}$ yield doubles while the yields of $\mathrm{CO}, \mathrm{CH}_{4}$ and $\mathrm{C}_{2+}$ greatly decrease compared with those of CS. This is mainly because $\mathrm{KCl}-\mathrm{ZnCl}_{2}$ promotes the dehydrogenation of volatile. However, $\mathrm{LiCl}-\mathrm{KCl}$ and $\mathrm{LiCl}-\mathrm{NaCl}-\mathrm{KCl}$ have a trivial effect on gas products. Only the yield of $\mathrm{H}_{2}$ increased slightly and the yields of other gases decreased.

The addition of $\mathrm{Li}_{2} \mathrm{CO}_{3}-\mathrm{K}_{2} \mathrm{CO}_{3}$ and $\mathrm{Li}_{2} \mathrm{CO}_{3}-\mathrm{Na}_{2} \mathrm{CO}_{3}-\mathrm{K}_{2} \mathrm{CO}_{3}$ slightly reduced the yield of $\mathrm{CH}_{4}$. While the yield of $\mathrm{C}_{2+}$ gas remained basically unchanged, the yield of $\mathrm{H}_{2}$ and $\mathrm{CO}_{2}$ increased. It is worth noting that the output of $\mathrm{CO}$ increased significantly, which is attributed to the intermolecular redox reaction of $\mathrm{Li}_{2} \mathrm{CO}_{3}$ in the molten salt as shown in equation (3) to produce $\mathrm{CO}$ [36]. Although there is another reaction (4) at the same time to maintain the balance of the whole molten salt system.

$\mathrm{Li}_{2} \mathrm{CO}_{3}+\mathrm{C} \rightarrow 2 \mathrm{CO}+\mathrm{Li}_{2} \mathrm{O}$

$\mathrm{Li}_{2} \mathrm{O}+\mathrm{CO}_{2} \rightarrow \mathrm{Li}_{2} \mathrm{CO}_{3}$

The reaction rate of (3) is much slower than that of (4). Therefore, the duration of $30 \mathrm{~min}$ is not enough to consume the char completely. Meanwhile, the $\mathrm{CO}_{2}$ produced by pyrolysis in the reaction atmosphere ensure that the molten salt can be basically kept stable without excessive

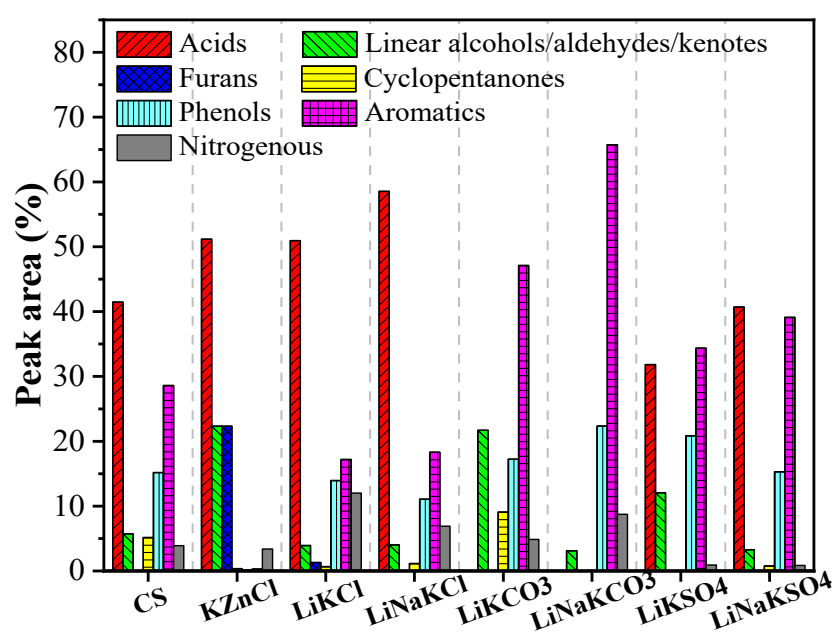

Fig. 5. The relative content of typical chemical compounds in bio-oil from CS pyrolysis and CS pyrolysis within different molten salt systems.

weight loss. According to the composition of $\mathrm{Li}_{2} \mathrm{CO}_{3}-\mathrm{K}_{2} \mathrm{CO}_{3}$ and $\mathrm{Li}_{2} \mathrm{CO}_{3}-$ $\mathrm{Na}_{2} \mathrm{CO}_{3}-\mathrm{K}_{2} \mathrm{CO}_{3}$, the former group contains more $\mathrm{Li}_{2} \mathrm{CO}_{3}$. Hence it will produce more $\mathrm{CO}$ and consume more $\mathrm{CO}_{2}$ via (3) and (4). This analytical result is consistent with the difference in $\mathrm{CO}$ and $\mathrm{CO}_{2}$ output obtained from the experiment.

The presence of $\mathrm{Li}_{2} \mathrm{SO}_{4}-\mathrm{K}_{2} \mathrm{SO}_{4}$ and $\mathrm{Li}_{2} \mathrm{SO}_{4}-\mathrm{Na}_{2} \mathrm{SO}_{4}-\mathrm{K}_{2} \mathrm{SO}_{4}$ reduced the yield of $\mathrm{H}_{2}$ and increased the yield of $\mathrm{CO}$, while $\mathrm{CO}_{2}$ output increased significantly from $3.59 \mathrm{mmol} / \mathrm{g}$ to $17.59 \mathrm{mmol} / \mathrm{g}$ and $16.67 \mathrm{mmol} / \mathrm{g}$ respectively. It can be explained by the rapid proceeding of reactions between char and sulfates during the pyrolysis process, as shown in equations (5)-(7). In this study, char was almost completely converted into $\mathrm{CO}_{2}$ no matter in binary or ternary sulfates system. This is consistent with the above changes in product distribution and the significant increase in sulfate weight loss.

$\mathrm{Li}_{2} \mathrm{SO}_{4}+2 \mathrm{C} \rightarrow \mathrm{Li}_{2} \mathrm{~S}+2 \mathrm{CO}_{2}$

$\mathrm{Na}_{2} \mathrm{SO}_{4}+2 \mathrm{C} \rightarrow \mathrm{Na}_{2} \mathrm{~S}+2 \mathrm{CO}_{2}$

$\mathrm{K}_{2} \mathrm{SO}_{4}+2 \mathrm{C} \rightarrow \mathrm{K}_{2} \mathrm{~S}+2 \mathrm{CO}_{2}$

Table 2 shows the gas composition of pyrolysis products obtained from different molten salts. The LHV and GECE are the evaluation indicators for gas products, apart from which the total output of $\mathrm{H}_{2}+\mathrm{CO}$ is another focus of attention since the target gas product of molten salt pyrolysis is generally $\mathrm{H}_{2}$ or syngas $\left(\mathrm{H}_{2}+\mathrm{CO}\right)$. Since alkali metal chlorides have little influence on gas composition, the values of LHV and GECE do not change significantly compared with that of the CS sample. Though the higher value of $\mathrm{H}_{2} / \mathrm{CO}$ suggests the potential for chloride to be used in the production of $\mathrm{H}_{2}$-rich gas. Gas products obtained from $\mathrm{KCl}-\mathrm{ZnCl}_{2}$ confirm this possibility more significantly, with the $\mathrm{H}_{2} / \mathrm{CO}$ ratio reaching 1.69 and $42.22 \mathrm{vol}_{\%} \mathrm{H}_{2}$ in gas composition.

The addition of carbonates greatly increases the content of $\mathrm{CO}$ in the gas products compared to the CS sample, up to $58.16 \mathrm{vol} \%$ and $54.52 \mathrm{vol}$

Table 2

Product composition, LHV and GECE of gas samples from CS pyrolysis and CS pyrolysis within different molten salt systems.

\begin{tabular}{|c|c|c|c|c|c|c|c|c|}
\hline Samples & $\mathrm{H}_{2}$ (vol.\%) & CO (vol.\%) & $\mathrm{CH}_{4}$ (vol.\%) & $\mathrm{C}_{2+}$ (vol.\%) & $\mathrm{CO}_{2}$ (vol.\%) & $\mathrm{H}_{2} / \mathrm{CO}$ & LHV MJ/Nm ${ }^{3}$ & GECE (\%) \\
\hline CS & 20.42 & 36.26 & 12.58 & 4.16 & 26.57 & 0.56 & 14.04 & 24.72 \\
\hline $\mathrm{KCl}-\mathrm{ZnCl}_{2}$ & 42.22 & 24.99 & 5.21 & 1.36 & 26.22 & 1.69 & 10.48 & 17.66 \\
\hline $\mathrm{LiCl}-\mathrm{KCl}$ & 26.22 & 31.69 & 11.11 & 3.31 & 27.66 & 0.83 & 13 & 21.71 \\
\hline LiCl-NaCl-KCl & 26.07 & 31.71 & 11.26 & 3.76 & 27.2 & 0.82 & 13.34 & 22.56 \\
\hline $\mathrm{Li}_{2} \mathrm{CO}_{3}-\mathrm{K}_{2} \mathrm{CO}_{3}$ & 17.27 & 58.16 & 4.62 & 2.2 & 17.75 & 0.30 & 12.31 & 42.55 \\
\hline $\mathrm{Li}_{2} \mathrm{CO}_{3}-\mathrm{Na}_{2} \mathrm{CO}_{3}-\mathrm{K}_{2} \mathrm{CO}_{3}$ & 16 & 54.52 & 5.7 & 2.46 & 21.33 & 0.29 & 12.27 & 40.32 \\
\hline $\mathrm{Li}_{2} \mathrm{SO}_{4}-\mathrm{K}_{2} \mathrm{SO}_{4}$ & 6.39 & 21.29 & 6.48 & 2.55 & 63.29 & 0.30 & 7.39 & 26.77 \\
\hline $\mathrm{Li}_{2} \mathrm{SO}_{4}-\mathrm{Na}_{2} \mathrm{SO}_{4}-\mathrm{K}_{2} \mathrm{SO}_{4}$ & 6.56 & 24.57 & 6.65 & 2.64 & 59.58 & 0.27 & 7.94 & 28.97 \\
\hline
\end{tabular}


Table 3

Ultimate analysis of char derived from CS pyrolysis and CS pyrolysis within different molten salt systems.

\begin{tabular}{|c|c|c|c|c|c|c|}
\hline \multirow[t]{2}{*}{ Char samples } & \multicolumn{4}{|c|}{ Ultimate (wt.\%) daf } & \multicolumn{2}{|c|}{ Molar ratio } \\
\hline & $\mathrm{C}$ & $\mathrm{H}$ & $\mathrm{N}$ & $\mathrm{O}^{*}$ & $\mathrm{O} / \mathrm{C}$ & $\mathrm{H} / \mathrm{C}$ \\
\hline CS & 93.42 & 1.56 & 1.34 & 3.68 & 0.03 & 0.20 \\
\hline $\mathrm{KCl}-\mathrm{ZnCl}_{2}$ & 83.77 & 1.28 & 1.45 & 13.50 & 0.12 & 0.18 \\
\hline LiCl-KCl & 87.70 & 1.40 & 1.47 & 9.43 & 0.08 & 0.19 \\
\hline LiCl-NaCl-KCl & 85.20 & 1.43 & 1.40 & 11.97 & 0.11 & 0.20 \\
\hline $\mathrm{Li}_{2} \mathrm{CO}_{3}-\mathrm{K}_{2} \mathrm{CO}_{3}$ & 73.50 & 0.84 & 0.05 & 25.61 & 0.26 & 0.14 \\
\hline $\mathrm{Li}_{2} \mathrm{CO}_{3}-\mathrm{Na}_{2} \mathrm{CO}_{3}-\mathrm{K}_{2} \mathrm{CO}_{3}$ & 71.95 & 0.82 & 0.05 & 27.18 & 0.28 & 0.14 \\
\hline
\end{tabular}

daf: Dry ash free, *: calculated by subtraction.

$\%$ CO obtained from $\mathrm{Li}_{2} \mathrm{CO}_{3}-\mathrm{K}_{2} \mathrm{CO}_{3}$ and $\mathrm{Li}_{2} \mathrm{CO}_{3}-\mathrm{Na}_{2} \mathrm{CO}_{3}-\mathrm{K}_{2} \mathrm{CO}_{3}$ respectively. Since the heating value of per unit volume $\mathrm{CO}$ is smaller than that of alkanes, the LHV of the gas product is slightly lower than that of the CS. However, from the giant increase of GECE, it could be seen that the presence of carbonates promotes the transformation of biomass energy in the feedstock to chemical energy in gas products. Although the gas yields within the sulfates systems are higher than that of CS or other molten salt systems, the large proportion of $\mathrm{CO}_{2}$ and the unsatisfactory value of LHV and GECE indicate that sulfate is unpromising for the preparation of pyrolysis gas products.

\subsubsection{Oil product}

Fig. 5 shows the composition of bio-oil obtained from CS pyrolysis and those with different molten salts. The relative content of each component is characterized by their percentage of peak area. For KCl$\mathrm{ZnCl}_{2}$, the relative contents of acids, linear alcohols/aldehydes/ketones are higher than those of CS, while cyclopentanones, phenols and aromatic hydrocarbons are almost undetected. This is mainly because $\mathrm{ZnCl}_{2}$ promotes the generation of carbon, which reduces the heavy components in the bio-oil and increases the relative contents of light components of acids and furans. After adding $\mathrm{LiCl}-\mathrm{KCl}$ or $\mathrm{LiCl}-\mathrm{NaCl}-\mathrm{KCl}$, the content of acids in the bio-oil exceeds $50 \%$, while the content of other components does not change much compared to CS. However, higher acidity worsens the equipment corrosion, which is unfavorable for the bio-oil further application.

The existence of carbonates $\mathrm{Li}_{2} \mathrm{CO}_{3}-\mathrm{K}_{2} \mathrm{CO}_{3}$ and $\mathrm{Li}_{2} \mathrm{CO}_{3}-\mathrm{Na}_{2} \mathrm{CO}_{3}-$ $\mathrm{K}_{2} \mathrm{CO}_{3}$ significantly reduces the acids in bio-oil. According to previous study [14], this phenomenon could be attributed to the enhanced catalytic cracking of carboxylic acids or the conversion of other acidic substance qualified by the molten salts. The content of phenols has increased, while the promotion of aromatics has a more significant performance. They increase from $28.6 \%$ in the pyrolysis of the CS to $47.1 \%$ and $65.8 \%$, respectively. This is because carbonate facilitates the further cyclization polycondensation of pyrolysis intermediate products, thereby forming more aromatic hydrocarbons. For the pyrolysis of biomass in sulfates, the composition of bio-oil components does not change much compared to the original pyrolysis.

The quality of bio-oil depends on the organic components, which requires it not only has thermochemical stability but also favors subsequent value-added processing. It can be seen from the above that there is a high content of acids in bio-oil. They are unstable and corrosive due to high oxygen content, which is detrimental to the subsequent utilization

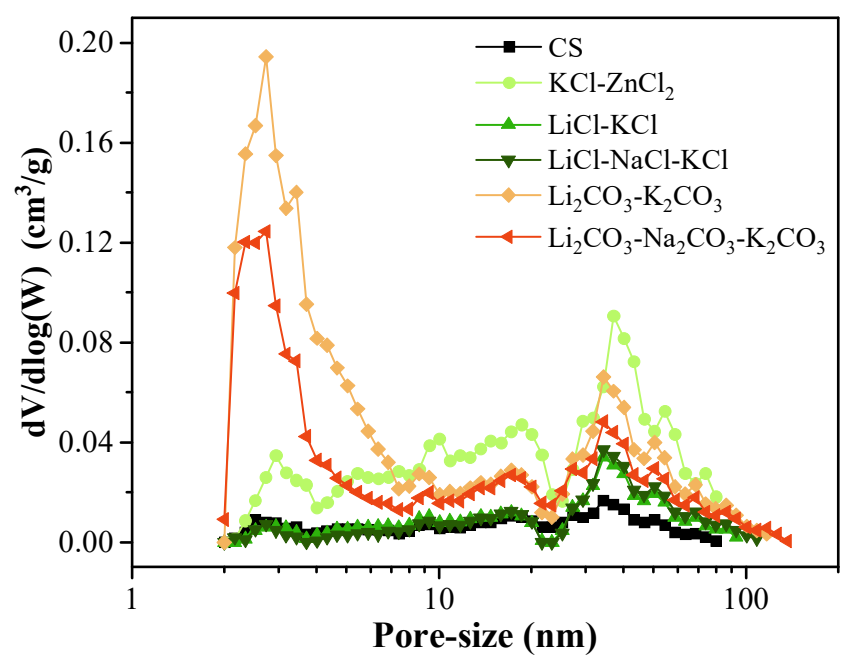

Fig. 6. Pore-size distribution of char derived from CS pyrolysis and CS pyrolysis within different molten salt systems.

of bio-oil. Therefore, it is necessary to reduce the content of acids in the bio-oil. In the meantime, phenols and aromatic hydrocarbons can be further transformed into high value-added products, the enrichment of which can benefit the subsequent utilization of pyrolysis oil products. Considering the composition of acids, phenols and aromatic hydrocarbons, the adaptability of different molten salts for the preparation of oil products from biomass pyrolysis is ranked from excellent to poor as follows: carbonates, sulfates, chlorides.

\subsubsection{Char product}

Table 3 shows the elemental analysis results of pyrolytic char. It can be found that most of the components in bio-char are carbon elements (93\%), with only a small amount of O, $\mathrm{H}$ and $\mathrm{N}$ elements. With the hightemperature process at $850{ }^{\circ} \mathrm{C}$, char structure gradually forms aromatization or graphitization. It should be pointed out that the sulfates $\mathrm{Li}_{2} \mathrm{SO}_{4}-\mathrm{K}_{2} \mathrm{SO}_{4}$ and $\mathrm{Li}_{2} \mathrm{SO}_{4}-\mathrm{Na}_{2} \mathrm{SO}_{4}-\mathrm{K}_{2} \mathrm{SO}_{4}$ can react with char. Therefore, the char is completely converted into gas (mainly $\mathrm{CO}_{2}$ ), and unable to be collected as mentioned before. Only chlorides and carbonates were compared from the aspect of pyrolysis char product.

With the addition of chlorides, the content of $\mathrm{C}$ and $\mathrm{H}$ in char decreased, while the content of $\mathrm{O}$ increased, corresponding to the increase of $\mathrm{O} / \mathrm{C}$ ratio. And with the presence of carbonates, the relative contents of elements $\mathrm{C}, \mathrm{H}, \mathrm{N}$ greatly reduced, O content rose sharply, resulting in elevated $\mathrm{O} / \mathrm{C}$ ratio. The high $\mathrm{O}$ content indicates that char contains a large number of oxygen-containing functional groups, which may have higher reactivity. With the influence of carbonates, most $\mathrm{N}$-containing substances are decomposed and precipitated. In addition, a lower $\mathrm{H} / \mathrm{C}$ ratio of char was observed with the carbonate pyrolysis system, which might indicate the promotion of carbonates on the aromatization of char.

Pore characteristics of pyrolysis char products in each group are shown in Table 4, and the pore size distribution is shown in Fig. 6. The char obtained from the cotton stalk without molten salt at $850{ }^{\circ} \mathrm{C}$ is possess with moderate pore structure, with specific surface area and pore volume reaching $222 \mathrm{~m}^{2} / \mathrm{g}$ and $0.1395 \mathrm{~cm}^{3} / \mathrm{g}$, respectively. The

Table 4

Pore characteristics of char derived from CS pyrolysis and CS pyrolysis within different molten salt systems.

\begin{tabular}{|c|c|c|c|c|c|}
\hline Char samples & BET specific area $\left(\mathrm{m}^{2} / \mathrm{g}\right)$ & Microporous area $\left(\mathrm{m}^{2} / \mathrm{g}\right)$ & Total pore volume $\left(\mathrm{cm}^{3} / \mathrm{g}\right)$ & Micropore volume $\left(\mathrm{cm}^{3} / \mathrm{g}\right)$ & Average pore-size (nm) \\
\hline CS & 222.31 & 179.93 & 0.1395 & 0.0978 & 3.88 \\
\hline $\mathrm{KCl}-\mathrm{ZnCl}_{2}$ & 268.84 & 180.02 & 0.2294 & 0.1022 & 5.62 \\
\hline LiCl-KCl & 161.10 & 124.05 & 0.1176 & 0.0700 & 5.08 \\
\hline LiCl-NaCl-KCl & 113.10 & 82.66 & 0.0897 & 0.0468 & 5.61 \\
\hline $\mathrm{Li}_{2} \mathrm{CO}_{3}-\mathrm{K}_{2} \mathrm{CO}_{3}$ & 889.15 & 521.51 & 0.5558 & 0.2905 & 2.93 \\
\hline $\mathrm{Li}_{2} \mathrm{CO}_{3}-\mathrm{Na}_{2} \mathrm{CO}_{3}-\mathrm{K}_{2} \mathrm{CO}_{3}$ & 821.55 & 511.14 & 0.5092 & 0.2961 & 2.86 \\
\hline
\end{tabular}



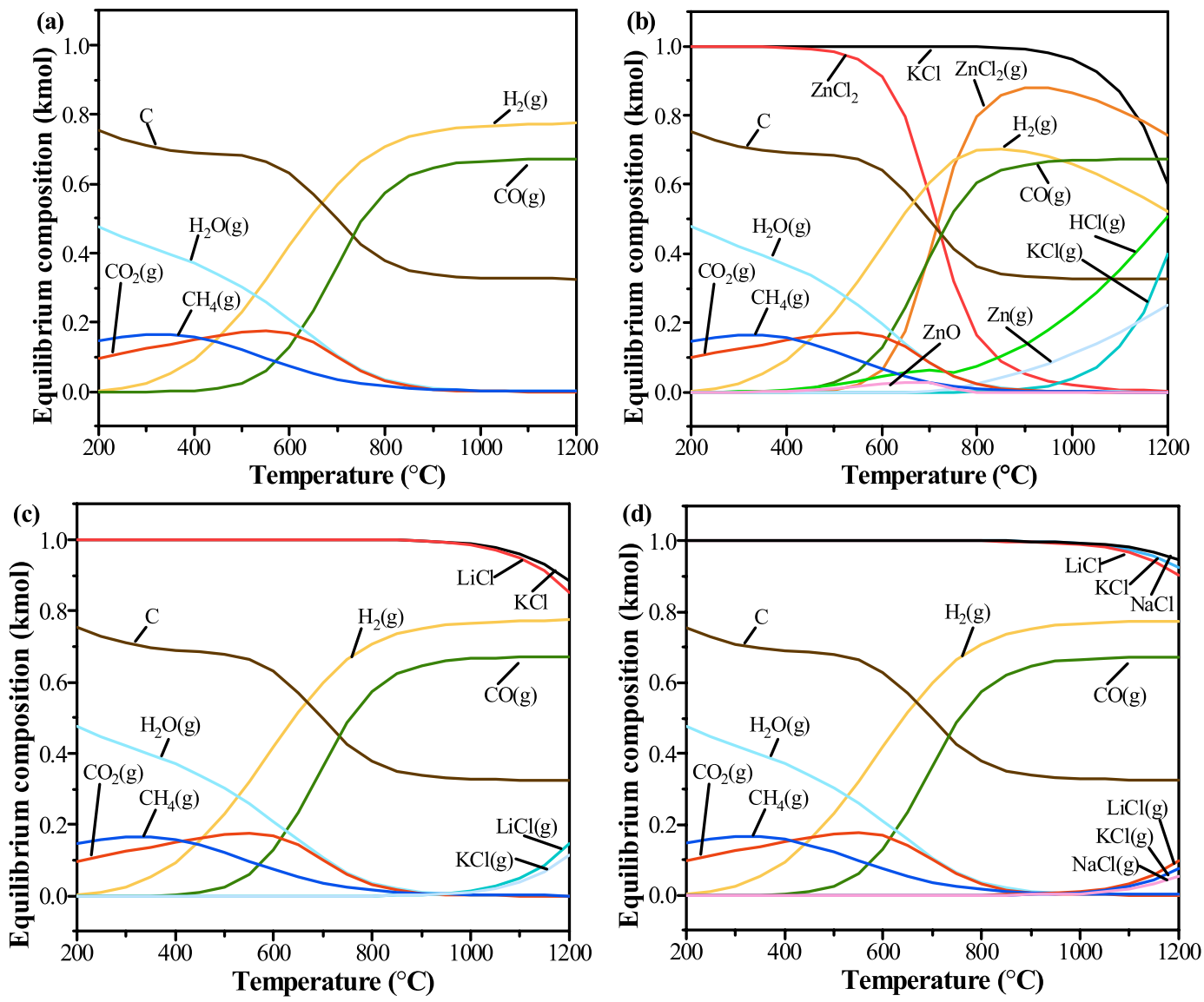

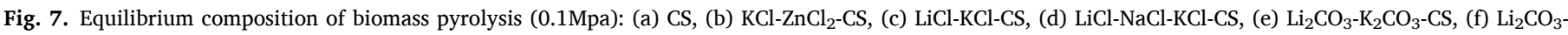
$\mathrm{Na}_{2} \mathrm{CO}_{3}-\mathrm{K}_{2} \mathrm{CO}_{3}-\mathrm{CS}$, (g) Li $\mathrm{LO}_{4}-\mathrm{K}_{2} \mathrm{SO}_{4}-\mathrm{CS}$, (h) $\mathrm{Li}_{2} \mathrm{SO}_{4}-\mathrm{Na}_{2} \mathrm{SO}_{4}-\mathrm{K}_{2} \mathrm{SO}_{4}-\mathrm{CS}$.

average pore diameter of the char is $3.88 \mathrm{~nm}$.

The presence of $\mathrm{KCl}-\mathrm{ZnCl}_{2}$ increases the specific surface area and pore volume of char, which demonstrates the activation effect of $\mathrm{ZnCl}_{2}$. This phenomenon is due to the improvement of mesoporous structure, and the average pore size also increases to $5.62 \mathrm{~nm}$. For the other two molten chloride systems, the performance of $\mathrm{LiCl}-\mathrm{KCl}$ and $\mathrm{LiCl}-\mathrm{NaCl}-\mathrm{KCl}$ is not optimistic. The specific surface area and pore volume are significantly reduced accompanied by less micropores in the char. The pore size distribution is centralized within $20-50 \mathrm{~nm}$ mesopore structure, and the average pore diameter increases to more than $5 \mathrm{~nm}$. This indicate that molten chloride enters into the intermediate char product at high temperature causing the rearrangement and the shrinking of the carbon skeleton with the breakdown of the pore structure $[37,38]$.

Different from the limited promotion or negative effects of chloride on the preparation of char, the presence of carbonate significantly contributes to the improvement of the pore characteristic. The specific surface area exceeds $800 \mathrm{~m}^{2} / \mathrm{g}$ and the pore volume exceeds $0.5 \mathrm{~cm}^{3} / \mathrm{g}$. The molten carbonate can intrude the interior char through the existing pores, and the carbonate can react with carbon and etch the carbon skeleton [37]. Hence the char product demonstrates an outstanding microporous structure that the pores with $2 \sim 5 \mathrm{~nm}$ diameter increase significantly and the average pore diameter is less than $3 \mathrm{~nm}$.

\subsection{Thermodynamic simulation}

In an attempt to explore the potential mechanism of the molten salt pyrolysis as well as molten salt stability with the presence of carbonaceous feedstock, HSC Chemistry software was applied to simulate molten salt pyrolysis of biomass since the actual pyrolysis process is very complicated and covers many reactions. The evolution of equilibrium components obtained from CS pyrolysis and CS pyrolysis within different molten salts are demonstrated in Fig. 7.

The equilibrium composition of biomass pyrolysis with the presence of $\mathrm{KCl}-\mathrm{ZnCl}_{2}$ is shown in Fig. 7(b). It can be found that the amount of the evolution of main products of biomass pyrolysis almost kept unchanged compared with that of CS depicted in Fig. 7(a), only $\mathrm{H}_{2}(\mathrm{~g})$ gradually decreased above $800{ }^{\circ} \mathrm{C}$. It indicated that $\mathrm{KCl}-\mathrm{ZnCl}_{2}$ has little influence on the biomass pyrolysis process. In addition, $\mathrm{ZnCl}_{2}$ transformed from solid to gaseous state and its content decreased above $500^{\circ} \mathrm{C}$, with the piling up of $\mathrm{HCl}(\mathrm{g})$ and $\mathrm{Zn}(\mathrm{g})$, which may be attributed to the reaction (8) and (9).

$\mathrm{ZnCl}_{2}+\mathrm{H}_{2} \mathrm{O}(\mathrm{g}) \rightarrow \mathrm{ZnO}+2 \mathrm{HCl}(\mathrm{g})$

$\mathrm{ZnCl}_{2}(\mathrm{~g})+\mathrm{H}_{2}(\mathrm{~g}) \rightarrow \mathrm{Zn}(\mathrm{g})+2 \mathrm{HCl}(\mathrm{g})$

The composition evolution of biomass pyrolysis within $\mathrm{LiCl}-\mathrm{KCl}$ and LiCl-NaCl-KCl is shown in Fig. 7(c) and 7(d), respectively. It can be found that the equilibrium composition of the main products of biomass pyrolysis under the influence of alkali metal chloride is almost the same as that of the CS. There is no interaction between molten salts and pyrolysis intermediate products while $\mathrm{LiCl}, \mathrm{KCl}$ and $\mathrm{NaCl}$ begin to transform from solid to gas above $900{ }^{\circ} \mathrm{C}$.

The influence of carbonate $\mathrm{Li}_{2} \mathrm{CO}_{3}-\mathrm{K}_{2} \mathrm{CO}_{3}$ and $\mathrm{Li}_{2} \mathrm{CO}_{3}-\mathrm{Na}_{2} \mathrm{CO}_{3}-\mathrm{K}_{2} \mathrm{CO}_{3}$ on the pyrolysis process of biomass is shown in Fig. 7 (e) and (f). When the temperature is lower than $550{ }^{\circ} \mathrm{C}$, the amount of pyrolysis products in carbonate is basically the same as CS. Carbonates have little influence on the pyrolysis of biomass and there is no reaction with pyrolysis intermediates below $550^{\circ} \mathrm{C}$. When the temperature is higher than $550{ }^{\circ} \mathrm{C}$, the carbonates gradually react with the intermediate products, so that 

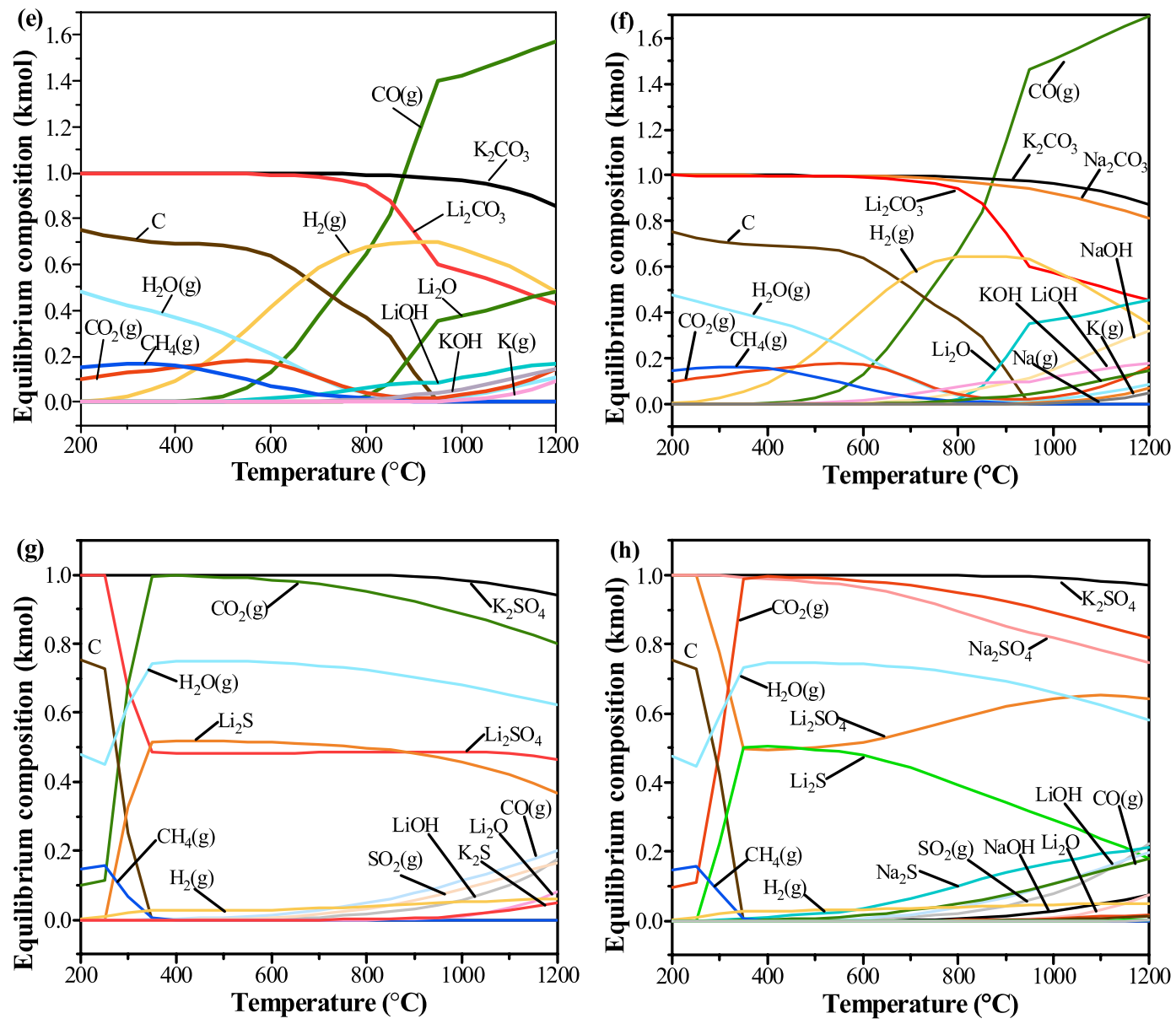

Fig. 7. (continued).

the amount of the main pyrolysis products of biomass also changes, in which reaction (10)-(14) may occur. The reaction pathway proposed is also consistent with the phenomenon of $\mathrm{Li}_{2} \mathrm{O}$ being found in carbonate residues in the reported study [39]. The effect of alkali metal carbonate on biomass pyrolysis becomes more significant after $750{ }^{\circ} \mathrm{C}$. In the following equations, $\mathrm{M}$ represents $\mathrm{Li}$, $\mathrm{Na}$ or $\mathrm{K}$. According to the HSC simulation results, the consumption of $\mathrm{Li}_{2} \mathrm{CO}_{3}$ is more obvious than that of other two carbonates. Moreover, it should be noted that, although the consumption of $\mathrm{Li}_{2} \mathrm{CO}_{3}$ is relatively large at $850{ }^{\circ} \mathrm{C}$, the gas contribution due to thermal decomposition of $\mathrm{Li}_{2} \mathrm{CO}_{3}$ is still negligible, which can be obtained from the results shown in Appendix Fig. A1.

$$
\begin{aligned}
& \mathrm{M}_{2} \mathrm{CO}_{3}+\mathrm{H}_{2} \mathrm{O}(\mathrm{g}) \rightarrow 2 \mathrm{MOH}+\mathrm{CO}_{2}(\mathrm{~g}) \\
& \mathrm{M}_{2} \mathrm{CO}_{3}+\mathrm{C} \rightarrow \mathrm{M}_{2} \mathrm{O}+2 \mathrm{CO}(\mathrm{g}) \\
& \mathrm{H}_{2}(\mathrm{~g})+\mathrm{CO}_{2}(\mathrm{~g}) \rightarrow \mathrm{CO}(\mathrm{g})+\mathrm{H}_{2} \mathrm{O}(\mathrm{g}) \\
& \mathrm{M}_{2} \mathrm{CO}_{3}+\mathrm{H}_{2}(\mathrm{~g}) \rightarrow 2 \mathrm{M}(\mathrm{g})+\mathrm{CO}_{2}(\mathrm{~g})+\mathrm{H}_{2} \mathrm{O}(\mathrm{g}) \\
& \mathrm{M}_{2} \mathrm{CO}_{3} \rightarrow \mathrm{M}_{2} \mathrm{O}+\mathrm{CO}_{2}(\mathrm{~g})
\end{aligned}
$$

The influence of sulfates $\mathrm{Li}_{2} \mathrm{SO}_{4}-\mathrm{K}_{2} \mathrm{SO}_{4}$ and $\mathrm{Li}_{2} \mathrm{SO}_{4}-\mathrm{Na}_{2} \mathrm{SO}_{4}-\mathrm{K}_{2} \mathrm{SO}_{4}$ on the pyrolysis process of biomass is shown in Fig. 7 (g) and (h). It can be found that the pyrolysis process of biomass changes abnormally after the addition of sulfates. The char and methane were rapidly consumed from $250{ }^{\circ} \mathrm{C}$ and completely disappeared at about $350{ }^{\circ} \mathrm{C}$. Almost all char derived from biomass pyrolysis was converted into $\mathrm{CO}_{2}(\mathrm{~g})$, and the reactions involved were mainly (15) and (16). As the temperature increased, sulfates went through a more complex conversion process with possible reactions (17) to (20).
Table 5

The consumption rate of molten salt in the equilibrium composition.

\begin{tabular}{ll}
\hline Composition of molten salts & Consumption rate at $850{ }^{\circ} \mathrm{C}(\%)$ \\
\hline $\mathrm{KCl} / \mathrm{ZnCl}$ & $0 / 5.1$ \\
$\mathrm{LiCl} / \mathrm{KCl}$ & $-0.04 / 0.04$ \\
$\mathrm{LiCl} / \mathrm{NaCl} / \mathrm{KCl}$ & $0 / 0 / 0$ \\
$\mathrm{Li}_{2} \mathrm{CO}_{3} / \mathrm{K}_{2} \mathrm{CO}_{3}$ & $11.97 / 1.04$ \\
$\mathrm{Li}_{2} \mathrm{CO}_{3} / \mathrm{Na}_{2} \mathrm{CO}_{3} / \mathrm{K}_{2} \mathrm{CO}_{3}$ & $11.98 / 3.59 / 1.22$ \\
$\mathrm{Li}_{2} \mathrm{SO}_{4} / \mathrm{K}_{2} \mathrm{SO}_{4}$ & $51.42 / 0.31$ \\
$\mathrm{Li}_{2} \mathrm{SO}_{4} / \mathrm{Na}_{2} \mathrm{SO}_{4} / \mathrm{K}_{2} \mathrm{SO}_{4}$ & $39.6 / 12.61 / 0.2$ \\
\hline
\end{tabular}

$\mathrm{M}_{2} \mathrm{SO}_{4}+2 \mathrm{C} \rightarrow \mathrm{M}_{2} \mathrm{~S}+2 \mathrm{CO}_{2}(\mathrm{~g})$

$\mathrm{M}_{2} \mathrm{SO}_{4}+\mathrm{CH}_{4} \rightarrow \mathrm{M}_{2} \mathrm{~S}+\mathrm{CO}_{2}(\mathrm{~g})+2 \mathrm{H}_{2} \mathrm{O}(\mathrm{g})$

$\mathrm{M}_{2} \mathrm{~S}+3 \mathrm{CO}_{2}(\mathrm{~g}) \rightarrow \mathrm{M}_{2} \mathrm{O}+\mathrm{SO}_{2}(\mathrm{~g})+3 \mathrm{CO}(\mathrm{g})$

$\mathrm{M}_{2} \mathrm{O}+\mathrm{H}_{2} \mathrm{O}(\mathrm{g}) \rightarrow 2 \mathrm{MOH}$

$\mathrm{M}_{2} \mathrm{SO}_{4}+\mathrm{H}_{2}(\mathrm{~g}) \rightarrow 2 \mathrm{MOH}+\mathrm{SO}_{2}(\mathrm{~g})$

$\mathrm{Li}_{2} \mathrm{~S}+\mathrm{M}_{2} \mathrm{SO}_{4} \rightarrow \mathrm{M}_{2} \mathrm{~S}+\mathrm{Li}_{2} \mathrm{SO}_{4}$

According to the equilibrium composition of the pyrolysis in Fig. 7, the consumption rate of the molten salt at $850^{\circ} \mathrm{C}$ can be calculated, as shown in Table 5. The consumption rate here is an indicator of how much molten salt participates in the chemical reaction, and the conversion between the solid and gaseous states of molten salt components is excluded. It can be found that alkali metal chlorides have no significant effect on the biomass 
pyrolysis process. The chloride salts $\mathrm{LiCl}-\mathrm{KCl}$ and $\mathrm{LiCl}-\mathrm{NaCl}-\mathrm{KCl}$ still have good stability with the presence of feedstock, while only a small amount of $\mathrm{ZnCl}_{2}$ in $\mathrm{KCl}-\mathrm{ZnCl}_{2}$ participates in the reaction.

However, oxyacid salts have a significant impact on the biomass pyrolysis process. This is mainly due to the char can react with the oxyacid salt. For carbonates, $\mathrm{Li}_{2} \mathrm{CO}_{3}$ is the main component involved in biomass pyrolysis reaction, whose consumption rate almost reaches $12 \%$ both in binary $\mathrm{Li}_{2} \mathrm{CO}_{3}-\mathrm{K}_{2} \mathrm{CO}_{3}$ and ternary $\mathrm{Li}_{2} \mathrm{CO}_{3}-\mathrm{Na}_{2} \mathrm{CO}_{3}-\mathrm{K}_{2} \mathrm{CO}_{3}$. A large number of sulfates participate in the biomass conversion, among which $\mathrm{Li}_{2} \mathrm{SO}_{4}$ still dominates the decomposition of sulfates. The consumption rate of $\mathrm{Li}_{2} \mathrm{SO}_{4}$ is even up to $51.42 \%$ and $39.6 \%$ in the binary and ternary systems at $850{ }^{\circ} \mathrm{C}$, respectively. That $12.61 \%$ of $\mathrm{Na}_{2} \mathrm{SO}_{4}$ are consumed in the $\mathrm{Li}_{2} \mathrm{SO}_{4}-\mathrm{Na}_{2} \mathrm{SO}_{4}-\mathrm{K}_{2} \mathrm{SO}_{4}$ system is not neglectable as well.

\section{Conclusion}

It can be seen that the alkali metal chlorides have almost no effect on the distribution of biomass pyrolysis products. However, the presence of $\mathrm{ZnCl}_{2}$ can greatly increase the yield of $\mathrm{H}_{2}$ and bio-char, and its activation effect can bring special pore-structure to the char product. But its intensive tendency to volatilize at high temperatures limits its application in pyrolysis above $600{ }^{\circ} \mathrm{C}$. Alkali metal carbonates can reduce the yield of oil while improving quality and increase the gas yield especially syngas $\left(\mathrm{H}_{2}+\mathrm{CO}\right)$. In addition, alkali metal carbonates have distinguished activation effects and contribute to the formation of meso- and microporous carbon. The decomposition and consumption of carbonates (especially $\mathrm{Li}_{2} \mathrm{CO}_{3}$ ) cannot be ignored in the pyrolysis of biomass with high temperature and lack of $\mathrm{CO}_{2}$ atmosphere. In other words, the presence of $\mathrm{Li}_{2} \mathrm{CO}_{3}$ might be the main reason for the increase of $\mathrm{CO}$ yield according to the HSC simulation, though its transformation into $\mathrm{Li}_{2} \mathrm{O}$ also leads to its unsustainability as a biomass pyrolysis medium. Alkali metal sulfates have outstanding thermal stability themselves but there is an interaction between char and sulfates even at a low temperature of $250{ }^{\circ} \mathrm{C}$. Almost all the char would be transformed into $\mathrm{CO}_{2}$ during biomass pyrolysis, resulting in the impossibility of char preparation and the poor quality of gas products.

\section{CRediT authorship contribution statement}

Kuo Zeng: Writing - original draft, Software, Visualization, Conceptualization, Resources, Validation. Xinyi Yang: Methodology, Software, Visualization. Yingpu Xie: Methodology, Formal analysis. Haiping Yang: Writing - review \& editing, Methodology, Formal analysis. Jun Li: Investigation, Formal analysis, Visualization. Dian Zhong: Investigation, Formal analysis, Visualization. Hongyang Zuo: Investigation, Formal analysis, Visualization. Ange Nzihou: Resources. YouJian Zhu: Investigation, Formal analysis, Visualization. Hanping Chen: Validation.

\section{Declaration of Competing Interest}

The authors declare that they have no known competing financial interests or personal relationships that could have appeared to influence the work reported in this paper.

\section{Acknowledgement}

We greatly appreciate the financial support from National Key Research and Development Plan of China(2018YFB1501403) and National Natural Science Foundation of China (52076098, 51706083), International Cooperation Project of Shenzhen (GJHZ20190820102607238), Natural Science Foundation of Shenzhen (JCYJ20170818164006890).
Table A1

Data of alkali metal salts selected.

\begin{tabular}{|c|c|c|c|c|c|}
\hline Composition & $\begin{array}{l}\text { CAS } \\
\text { Number }\end{array}$ & Purity & $\begin{array}{l}\text { Density }(\mathrm{g} / \\
\left.\mathrm{cm}^{3}\right)\end{array}$ & $\begin{array}{l}\text { Melting } \\
\text { point }\left({ }^{\circ} \mathrm{C}\right)\end{array}$ & $\begin{array}{l}\text { Boiling } \\
\text { point }\left({ }^{\circ} \mathrm{C}\right)\end{array}$ \\
\hline $\mathrm{LiCl}$ & $\begin{array}{l}7447-41- \\
8\end{array}$ & $\mathrm{AR}$ & 2.06 & 605 & $1382^{S}$ \\
\hline $\mathrm{NaCl}$ & $\begin{array}{l}7647-14- \\
5\end{array}$ & $\mathrm{AR}$ & 2.16 & 801 & $1461^{S}$ \\
\hline $\mathrm{KCl}$ & $\begin{array}{l}7447-40- \\
7\end{array}$ & $\mathrm{AR}$ & 1.98 & 773 & $1420^{S}$ \\
\hline $\mathrm{ZnCl}_{2}$ & $\begin{array}{l}7646-85- \\
7\end{array}$ & $98 \%$ & 2.91 & 293 & $732^{S}$ \\
\hline $\mathrm{Li}_{2} \mathrm{CO}_{3}$ & $554-13-2$ & $\mathrm{AR}$ & 2.11 & 723 & $1310^{\mathrm{U}}$ \\
\hline $\mathrm{Na}_{2} \mathrm{CO}_{3}$ & $497-19-8$ & $\mathrm{AR}$ & 2.53 & 851 & $\mathrm{D}(>850)$ \\
\hline $\mathrm{K}_{2} \mathrm{CO}_{3}$ & $584-08-7$ & AR & 2.43 & 891 & $\mathrm{D}(>850)$ \\
\hline $\mathrm{Li}_{2} \mathrm{SO}_{4}$ & $\begin{array}{l}10377- \\
48-7\end{array}$ & $99 \%$ & 2.22 & 859 & $1377^{\mathrm{U}}$ \\
\hline $\mathrm{Na}_{2} \mathrm{SO}_{4}$ & $\begin{array}{l}7757-82- \\
6\end{array}$ & AR & 2.68 & 884 & $1700^{\mathrm{S}}$ \\
\hline $\mathrm{K}_{2} \mathrm{SO}_{4}$ & $\begin{array}{l}7778-80- \\
5\end{array}$ & AR & 2.66 & 1067 & $1689^{\mathrm{U}}$ \\
\hline
\end{tabular}

AR: Analytical Reagent.

S: Stable above boiling point; U: Decompose at unknown temperature. $\mathrm{D}(>850)$ : Decompose below boiling point but above $850^{\circ} \mathrm{C}$.
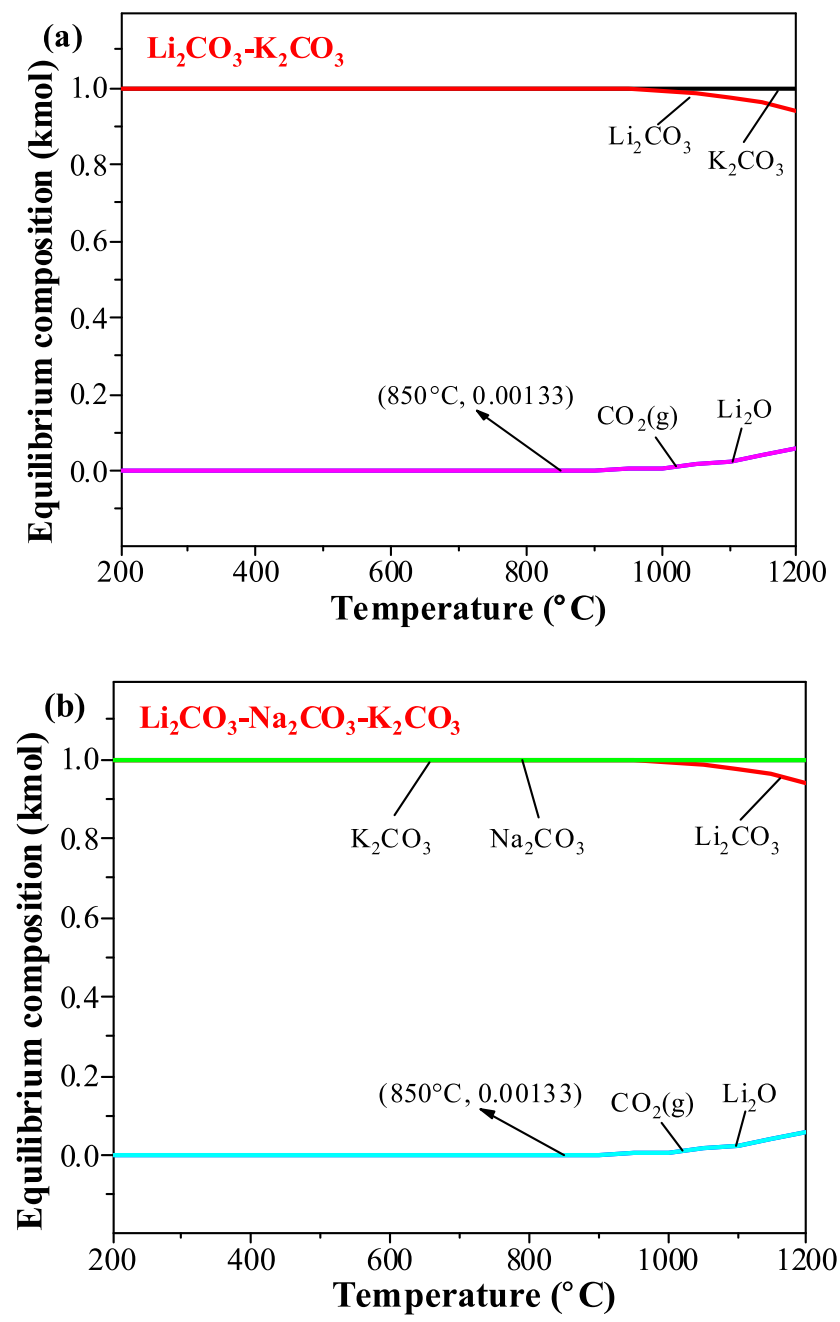

Fig. A1. Equilibrium composition of molten salt (0.1Mpa): (a) $\mathrm{Li}_{2} \mathrm{CO}_{3}-\mathrm{K}_{2} \mathrm{CO}_{3}$, (b) $\mathrm{Li}_{2} \mathrm{CO}_{3}-\mathrm{Na}_{2} \mathrm{CO}_{3}-\mathrm{K}_{2} \mathrm{CO}_{3}$ 


\section{References}

[1] Yaman S. Pyrolysis of biomass to produce fuels and chemical feedstocks. Energy Conv Manag 2004;45(5):651-71.

[2] Li J, Xiong Z, Zeng K, Zhong D, et al. Characteristics and evolution of nitrogen in the heavy components of algae pyrolysis bio-oil. Environ. Sci. Technol. 2021;55(9): 6373-85.

[3] Jiang HT, Ai N, Wang M, Ji DX, Ji JB. Experimental study on thermal pyrolysis of biomass in molten salt media. Electrochemistry 2009;77(8):730-5.

[4] Adinberg R, Epstein M, Karni J. Solar gasification of biomass: a molten salt pyrolysis study. J Solar Energy Eng-Trans ASME 2004;126(3):850-7.

[5] Wei Yi, Tang J, Xie J, Shen C. Molten alkali carbonates pyrolysis of digestate for phenolic productions. J Cleaner Prod 2019;225:143-51.

[6] Rizkiana J, Guan G, Widayatno WB, Hao X, Wang Z, Zhang Z, et al. Oil production from mild pyrolysis of low-rank coal in molten salts media. Appl Energy 2015;154: 944-50.

[7] Hathaway BJ, Honda M, Kittelson DB, Davidson JH. Steam gasification of plant biomass using molten carbonate salts. Energy 2013;49:211-7.

[8] Ong HC, Chen W-H, Farooq A, Gan YY, Lee KT, Ashokkumar V. Catalytic thermochemical conversion of biomass for biofuel production: a comprehensive review. Renew Sustain Energy Rev 2019;113:109266. https://doi.org/10.1016/j. rser.2019.109266.

[9] Peng Q, Wei X, Ding J, Yang J, Yang X. High-temperature thermal stability of molten salt materials. Int J Energy Res 2008;32(12):1164-74.

[10] Olivares RI, Chen C, Wright S. The thermal stability of molten lithium-sodium-potassium carbonate and the influence of additives on the melting point. J Sol Energy Eng 2012;134(4):041002.

[11] Pramod KM, Rao PVC, Choudary NV, Ramesh K. Novel methodology to prepare homogenous ternary molten salts for concentrated solar power applications and their thermo-physical characterization. Appl Therm Eng 2016;109:906-10.

[12] Serrano D, Horvat A, Sobrino C, Sánchez-Delgado S. Thermochemical conversion of C. cardunculus L. in nitrate molten salts. Appl Therm Eng 2019;148:136-46.

[13] Yin H, Lu B, Xu Y, Tang D, Mao X, Xiao W, et al. Harvesting capacitive carbon by carbonization of waste biomass in molten salts. Environ Sci Technol 2014;48(14): 8101-8.

[14] Xie Y, Zeng K, Flamant G, Yang H, Liu N, He X, et al. Solar pyrolysis of cotton stalk in molten salt for bio-fuel production. Energy 2019;179:1124-32.

[15] He X, Zeng K, Xie Y, Flamant G, Yang H, Yang X, et al. The effects of temperature and molten salt on solar pyrolysis of lignite. Energy 2019;181:407-16.

[16] Zeng K, Li J, Xie Y, Yang H, Yang X, Zhong D, et al. Molten salt pyrolysis of biomass: the mechanism of volatile reforming and pyrolysis. Energy 2020;213: 118801. https://doi.org/10.1016/j.energy.2020.118801.

[17] Nygard HS, Olsen E. Effect of salt composition and temperature on the thermal behavior of beech wood in molten salt pyrolysis. In: Naerland TU, editor Renewable Energy Research Conference, Rerc 2014. 58:221-8.

[18] Yeboah YD, Xu Y, Sheth A, Godavarty A, Agrawal PK. Catalytic gasification of coal using eutectic salts: identification of eutectics. Carbon 2003;41(2):203-14.

[19] Shang H, Lu Y, Zhao F, Chao C, Zhang B, Zhang H. Preparing high surface area porous carbon from biomass by carbonization in a molten salt medium. RSC Adv 2015;5(92):75728-34.
[20] Wu T, Zhang W, Jin X, Liang X, Sui G, Yang X. Efficient reclamation of carbon fibers from epoxy composite waste through catalytic pyrolysis in molten $\mathrm{ZnCl} 2$. RSC Adv 2019;9(1):377-88.

[21] Kudsy M, Kumazawa H. Pyrolysis of kraft lignin in the presence of molten ZnCl2KCl mixture. Can J Chem Eng 1999;77(6):1176-84.

[22] Ai N, Zeng G, Zhou H, He Y. Co-production of activated carbon and bio-oil from agricultural residues by molten salt pyrolysis. Bioresources 2013;8(2):1551-62.

[23] Sada E, Kumazawa H, Kudsy M. Pyrolysis of lignins in molten salt media. Ind Eng Chem Res 1992;31(2):612-6.

[24] Chen W, Yang H, Chen Y, Chen Xu, Fang Y, Chen H. Biomass pyrolysis for nitrogencontaining liquid chemicals and nitrogen-doped carbon materials. J Anal Appl Pyrol 2016;120:186-93.

[25] Zeng K, Yang Q, Zhang Y, Mei Y, Wang X, Yang H, et al. Influence of torrefaction with $\mathrm{Mg}$-based additives on the pyrolysis of cotton stalk. Bioresour Technol 2018; 261:62-9.

[26] Zeng K, Gauthier D, Minh DP, Weiss-Hortala E, Nzihou A, Flamant G. Characterization of solar fuels obtained from beech wood solar pyrolysis. Fuel 2017;188:285-93.

[27] Wang C, Hu X, Matsuura H, Tsukihashi F. Evaporation kinetics of the molten PbCl2ZnCl2 system from 973 to 1073 K. ISIJ Int 2007;47(3):370-6.

[28] Jiang Y, Sun Y, Bruno F, Li S. Thermal stability of Na2CO3 -Li2CO3 as a high temperature phase change material for thermal energy storage. Thermochim Acta 2017;650:88-94.

[29] Kim H-J, Ahn Y-S. Coating of chromium and titanium carbide on diamond particles in molten LiCl-KCl-NaCl. J Alloy Compd 2020;849:156508. https://doi.org/ 10.1016/j.jallcom.2020.156508.

[30] Janz GJ. II.G - THERMAL DATA. In: Janz GJ, editor Molten Salts Handbook. Academic Press; 1967, p. 184-211.

[31] Branco JB, Lopes G, Ferreira AC, Leal JP. Catalytic oxidation of methane on KClMClx (M=Li, Mg Co, Cu, Zn) eutectic molten salts. J Mol Liq 2012;171:1-5.

[32] Basin AS, Kaplun AB, Meshalkin AB, Uvarov NF. The LiCl-KCl binary system. Russ J Inorg Chem 2008;53(9):1509-11.

[33] Liu W-J, Jiang H, Yu H-Q. Development of biochar-based functional materials: toward a sustainable platform carbon material. Chem Rev 2015;115(22): 12251-85.

[34] Nzihou A, Stanmore B, Sharrock P. A review of catalysts for the gasification of biomass char, with some reference to coal. Energy 2013;58:305-17.

[35] Di Blasi C, Galgano A, Branca C. Influences of the chemical state of alkaline compounds and the nature of alkali metal on wood pyrolysis. Ind Eng Chem Res 2009;48(7):3359-69.

[36] Nagase K, Shimodaira T, Itoh M, Zheng Y. Kinetics and mechanisms of the reverse Boudouard reaction over metal carbonates in connection with the reactions of solid carbon with the metal carbonates. Phys Chem Chem Phys 1999;1(24):5659-64.

[37] Nayak A, Bhushan B, Gupta V, Sharma P. Chemically activated carbon from lignocellulosic wastes for heavy metal wastewater remediation: effect of activation conditions. J Colloid Interface Sci 2017;493:228-40.

[38] Li B, Hu J, Xiong He, Xiao Y. Application and properties of microporous carbon activated by $\mathrm{ZnCl2}$ : adsorption behavior and activation mechanism. ACS Omega 2020;5(16):9398-407.

[39] Ratchahat S, Kodama S, Tanthapanichakoon W, Sekiguchi H. Combined molten salt-Ni/Al2O3 as synergistic medium for high-quality syngas production. Chem Eng J 2015;278:224-33. 